\title{
Constructions License Verb Frames
}

Laura A. Michaelis

University of Colorado Boulder

\section{Introduction ${ }^{\mathrm{i}}$}

Where does a verb's frame come from? The obvious answer is the verb itself, and this is the answer that syntacticians have traditionally provided, whether they describe predicator-argument relations as syntactic sisterhood relations or as lexical properties (the predicator's combinatoric potential, or valence). Thus, Haegeman, in her introduction to Government and Binding theory, states, "the thematic structure of a predicate, encoded in the theta grid, will determine the minimal components of the sentence" (Haegeman 1994: 55). Similarly, Bresnan, in her introduction to Lexical Functional Grammar (LFG), states, "[o]n the semantic side, argument structure represents the core participants and events (states, processes) designated by a single predicator. [...] On the syntactic side, argument structure represents the minimal information needed to characterize the syntactic dependents of an argument-taking head" (Bresnan 2001: 304). In lexicalist theories like LFG, whenever the arguments of a verb can have more than one set of syntactic realizations, each distinct realization pattern corresponds to a different mapping from semantic roles to grammatical functions, as expressed in a unique lexical entry, and lexical entries, or classes of lexical entries, are related by lexical rules (Neidle 1994).

The drive to streamline lexical entries by removing predictable properties has led theorists to develop more general, putatively universal, mapping principles, as well as principles for deriving 
the semantic roles themselves, typically from the positions that they occupy in in a decomposed representation of the verb's event-structure properties. In this approach, as Van Valin and LaPolla (1997: 154) describe it, "[t]here is no need to specify the thematic relations that a verb takes; they follow without stipulation from the logical structure, since they follow by definition from its structure". Thus few syntacticians currently assume gestalt-like, semantically based verb classes of the type that figure in frame-semantic analysis, for example verbs denoting acts of theft, requesting or attaching (Ruppenhofer et al. 2002). But however they are construed, verbs and verb classes continue to be regarded as the only source of syntactically relevant meaning (Pinker 1989, Van Valin and LaPolla 1997, Levin and Rappaport Hovav 2005). Syntactically relevant meaning is generally identified with aspectual meaning and verb classes with aspectual classes. Syntactic theorists typically represent verb meanings through a form of decompositional analysis, inspired by Dowty 1979 and Jackendoff 1990, that picks out components of causation, change and/or stasis from the scene denoted by a verb (Croft 2012: Ch. 2). For example, in a discussion of Italian auxiliary selection, Levin and Rappaport (2005: 12ff) argue that accounts based on the change-of-state entailment are more predictive of essere selection than those that make use of gestalt-like semantic classes like 'verbs of bodily process'. At the same time, frame membership has been shown to predict certain verbal syntactic affordances, including null complementation (Ruppenhofer and Michaelis 2014).

While there are differing approaches to lexical-semantic representation, there is little dissent concerning the directionality of the syntax-semantics interface: the verb selects its frame but frames do not select verbs. It is difficult, however, to square this seeming truism with the observation, made by Goldberg 1995, 2006, Kaschak and Glenberg 2000, 2002, Partee and 
Borschev 2004 and Michaelis and Ruppenhofer 2001, among others, that verbs can appear in unexpected frames, which nonetheless make sense in context. For example, as shown in (1-3), single-argument activity verbs like melt and sparkle, which have nothing intrinsically to do with location, can appear in the 'locative inversion' pattern, resulting in what Bresnan (1994: 91) calls an 'overlay' of the locative-theme frame:

(1) In Maria's sticky hand melted a chocolate-chip ice-cream cone. (Birner and Ward 1998: 193)

(2) And in this lacey leafage fluttered a number of grey birds with black and white stripes and long tails. (Levin and Rappaport Hovav 1995: 226)

(3) Down at the harbor there is a teal-green clubhouse for socializing and parties. Beside it sparkles the community pool. (Vanity Fair, 8/01)

In (1-3), the verb appears to describe what an entity is doing while in its location (melting, fluttering, sparkling) rather than a location state per se. Looking at a similar class of examples in Russian, Borschev and Partee (2007: 158) observe, "[o]ne could say that THING and LOC are roles of the verb [be], but it is undoubtedly better to consider them roles of the participants of the situation (or state) of existing or of being located". They go on to point out that the situation of existing involves not only a location state but also a particular perspective on that state, which they describe with a visual analogy:

In an existential sentence, the LOC is chosen as the perspectival center; [the sentence asserts] of the LOC that it has THING in it. [...] An existential sentence is analogous to the way a security camera is fixed on a scene and records whatever is in that location. (Partee and Borschev 2007: 156) 
The security-camera metaphor aptly captures the stylistic effect of the locative-inversion pattern, but if we take it seriously we have to acknowledge that word meaning and syntactic meaning are far more similar than traditional models of syntax would care to admit. Like a word, a syntactic pattern may be conventionally associated with a highly elaborated semantic frame, including a perspectival one. This is the view taken in construction-based syntax, as described by Goldberg $(1995,2002,2006)$ and others. According to this view, argument-structure patterns are formmeaning pairings that denote situation types like those denoted by verbs (e.g., an event of transfer, a locational state). As a corollary, a verb's meaning and combinatory potential (or valence) can change to fit the meaning of a given construction (Goldberg 1995, 2002, 2006, Michaelis and Ruppenhofer 2001, Michaelis 2004). Argument-structure constructions in this model are conceived as constraints on classes of verb entries, which are in turn understood as feature-structure descriptions that specify values for the features that determine morphophonemic form, frame-semantic meaning, valence and syntactic category. The construction-based model of argument structure described in the works cited above is based on reconciling the verb's feature specifications with those of the construction, rather than the licensing of arguments by verbs. This reconciliation operation requires an overlap between the verb's semantic representation and that of the construction. Combining verb meaning and construction meaning requires interpreters to create a semantic link between the event denoted by the verb and that denoted by the construction. The possible 'linkage' relations, as described by Goldberg (1995: Ch. 2), include instance, means and manner. A result of this integration mechanism is valence augmentation: the set of arguments licensed by the construction may properly include that licensed by the verb with which the construction is combined. Examples of valence augmentation are given in (4-5): 
(4) Most likely they were fellow visitors, just panting up to the sky-high altar out of curiosity. (L. Davis, Last Act in Palmyra, p. 28)

(5) When a visitor passes through the village, young lamas stop picking up trash to mug for the camera. A gruff 'police monk' barks them back to work. (Newsweek 10/13/97)

In (4), pant, a verb that otherwise licenses only a single argument, appears with two: it denotes the manner of the directed-motion event denoted by the construction. In (5), bark, another otherwise monovalent activity verb, has two additional arguments, a direct object and an oblique expression that indicates direction; in this context, the verb denotes the means by which a (metaphorically construed) caused-motion event, denoted by the construction, occurs. Rather than presuming a nonce lexical entry for pant in which it means "move toward a goal while panting' and for bark in which it means 'move something from one place to another by barking', a constructionist presumes that the verbs in (4-5) mean what they always mean; arguments not licensed by the verb are licensed by the construction with which the verb combines. The constructional model of verbal syntactic variability is therefore more parsimonious than a lexicalist one: it uses a small number of argument-structure constructions and assumes that these constructions can alter verb meanings whenever there is a clash between a verb's meaning (and its valence) and a construction's meaning (and its valence), it limits the number of lexical entries needed for each verb.

The problem is, however, that the patterns we use for creating phrases are not supposed to denote anything: they combine symbols rather than being symbols themselves. Only words bear conventionally assigned meanings. In the prevailing view of meaning composition, syntactic rules do no more than determine what symbol sequences function as units for syntactic purposes 
(Kay and Michaelis 2012). So while syntactic rules assemble words and their dependent elements into phrases, and the phrases denote complex concepts like predicates and propositions, the rules cannot add conceptual content to that contributed by the words; nor can they alter the combinatoric properties of the words. On this view, which Jackendoff (1997: 48) describes as the "doctrine of syntactically transparent composition", "[a]11 elements of content in the meaning of a sentence are found in the lexical conceptual structures [...] of the lexical items composing the sentence". If the rules of syntactic combination do not add conceptual content to that contributed by the words, they should not be able to alter the combinatory potential of words. Thus, whatever the source of the 'extra' arguments found in examples like (4) and (5), it cannot reasonably be a syntactic rule.

In order to preserve a compositional model of sentence meaning, one might choose to view valence augmentation and other construal-based semantic effects on verbs as the products of lexical derivations that build up complex event structures from simpler ones. A model of this nature is proposed by Rappaport Hovav and Levin 1998 (henceforth, RHL; see also Levin 2000 and Levin and Rappaport Hovav 2005). Under this model, semantic verb classes are epiphenomenal, because it is the sum of a verb's meaning components, rather than the verb's semantic-class membership, that actually explains syntactic behaviors like auxiliary selection. Unlike the construction-based model outlined above, the RHL model is based on lexical projection; as they put it: "Many aspects of the syntactic structure of a sentence-in particular, the syntactic realization of arguments - are projected from the lexical properties of the verbs" (RHL: 97). Each of a verb's syntactic frames is associated with a distinct verb meaning, although every verb has one basic class membership. An implication of this model is that most verbs are 
polysemous, and many verbs are highly so. Since RHL assume (in accordance with Pinker 1989 and others) that the only syntactically relevant component of verb meaning is aspectual meaning, the more aspectual representations a verb has the more syntactic variation it will display, and vice versa. To represent verb meaning and semantic operations on verb meaning, RHL propose (a) a set of Aktionsart-based schemas and (b) an operation that augments one such schema up to another one. Both the schemas and the augmentation operation are independently motivated; they appear, for example, in the transition network used by Moens and Steedman 1988 to model aspectual type-shifts triggered by verb morphology. An example of one such shift is given in (6):

(6) Mary was winning the race (when she was tripped by Zola).

In (6) we see that the progressive construction, which seeks a durative event as its daughter, can combine with a verb denoting a momentaneous event (win) and in so doing create a construal in which winning is preceded by a preparatory process. In terms of the Moens and Steedman analysis, the progressive operator applies to the process phase of a culminated process (i.e., an accomplishment verb) that is derived from a culmination (i.e., an achievement verb) via augmentation (i.e., the addition of an activity representation or 'run-up process'). In the RHL model, verb meanings are represented by the set of event-structure templates given in Table 1. In these representations, variables represent participants licensed by the event-structure template, predicates in small caps (e.g., АCT) represent subevents and capitalized italic terms in angled brackets represent idiosyncratic meaning components contributed by whatever verb happens to combine with the template. 
Table 1. Event Structure Templates (based on Rappaport Hovav and Levin 1998)

\begin{tabular}{|l|l|}
\hline Aktionsart Class & Semantic Representation \\
\hline State & {$[\mathrm{x}<$ STATE $>]$ e.g., shine } \\
\hline Activity & {$[\mathrm{x}$ ACT $<$ MANNER $>]$ e.g., skip } \\
\hline Achievement & {$[$ BECOME $[\mathrm{x}<$ STATE $>]]$ e.g., sink } \\
\hline $\begin{array}{l}\text { Accomplishment (external } \\
\text { cause) }\end{array}$ & $\begin{array}{l}[\mathrm{x} \text { ACT }<M A N N E R>] \text { CAUSE }[\text { BECOME y }<\text { STATE }>]]] \\
\text { e.g., build }\end{array}$ \\
\hline Accomplishment & {$[\mathrm{x}$ CAUSE $[$ BECOME y $<$ STATE $>]]$ e.g., break } \\
\hline
\end{tabular}

The valence of the verb may be lower than, higher than or equal to the number of argument slots in the template. Argument roles licensed by event-structure templates are referred to as structure participants while those licensed only by the verb are referred to as constant participants. Thus, for example, activity verbs like chew or sweep are structurally intransitive: the second argument is a lexically licensed (constant) participant that does not fuse with any role of the activity eventstructure template. RHL propose two argument-realization conditions on verb-template unification:

(7) Argument realization condition 1: Each structure participant must be realized by an XP.

(8) Argument realization condition 2: Each XP must correspond to a subevent. 
According to the condition given in (7), which will be the focus of our attention in section 3.2, the second argument of an activity verb need not be realized, as it is a constant rather than a structural argument, while the second argument of an accomplishment verb, a structural argument, must be realized: *They hammered flat. Variations in the syntactic frame of a verb are viewed as resulting from semantic operations that transform one semantic representation into a more fully expanded semantic representation. Two such operations are given in (9-10):

$$
\begin{aligned}
& [\mathrm{x} \text { ACT }<\text { MANNER }>] \rightarrow[\mathrm{x} \text { ACT }<\text { MANNER }>\text { CAUSE }[\text { BECOME } \mathrm{y}<\text { STATE }>]]] \\
& {[\mathrm{x}<\text { STATE }>] \rightarrow[\text { BECOME }[\mathrm{x}<\text { STATE }>]]}
\end{aligned}
$$

The operation shown in (9) transforms an activity verb, as in (11), into an (externally caused) change-of-state verb, as in (12), via the addition of a CAUSE operator linking the activity representation to an achievement representation:

\section{(11) Shira skipped.}

(12) Shira skipped down the corridor.

(Note that in the representation of self-propelled motion, as in (12), the variables $x$ and $y$ will be equated.) The operation shown in (10) transforms a state verb, as in (13), into an achievement verb, as in (14), by adding the operator BECOME to the input state:

(13) She sat on the couch (as she spoke).

(14) She sat on the couch (after she came into the house).

While (13) describes the maintenance of a body posture, (14) describes movement into a new body posture. 
The RHL model preserves the strict version of compositionality alluded to above, in which conceptual content comes from the lexicon. In this model, a verb's syntactic frame, or combinatoric potential, comes from its semantic representation, rather than the inverse. We need not presume that syntactic rules, like the rule that pairs a verb like skip with a directional PP like down the hall, 'add meaning' to verbs. Instead, syntactic rules are syntactic in the traditional sense: they represent the constituents that are created when a lexical head (e.g., a verb) combines with the arguments and adjuncts that it semantically selects. In addition to ensuring that syntactic rules do no semantic work, the RHL model factors syntactic information out of lexical entries, allowing a set of putatively universal morphosyntactic realization rules to link participant roles to grammatical functions. Thus, RHL's model of the syntax-semantics interface achieves a strict separation of syntax and semantics. This is a desirable goal, since form and meaning are demonstrably two different levels of organization; for one thing, most lexical entailments (e.g., evaluative components of words like excuse (vs. justification) and credit (vs. blame) are simply “invisible to syntax" (Jackendoff 1997: 34).

In this paper, however, I will discuss five classes of phenomena that suggest that verbs have the arguments that they do not because their event-structure representations are subject to semantic operations but because they combine with grammatical constructions that have gestalt-like meanings similar to those of traditional frame-semantic classes. This in turn suggests that semantic gestalts like 'locative state', 'creation event' and 'directed motion event' cannot be replaced by an inventory of meaning components and rules for combining them. To capture the effects at issue, I will propose a formal model of argument-structure constructions based on Sign-Based Construction Grammar (SBCG), a formalized version of Construction Grammar 
(Fillmore et al. 1988, Goldberg 1995, Michaelis and Lambrecht 1996, Fillmore and Kay 1999) developed by Sag $(2010,2012)$ and others (see the papers in Boas and Sag 2012). The linguistic phenomena that I will discuss are as follows:

- Aspectual underspecification. A verb's syntactic behavior cannot always be traced to its Aktionsart classification(s).

- Null complementation. The circumstances under which a given argument of a given verb may be phonetically unrealized are not accurately described by augmentative operations on event structure of the type described by RHL.

- Weird sisterhood. Many verb frames specify sisterhood relations that are not predicted by the general-purpose constituency rules that combine heads and complements and heads and specifiers.

- Quantification of argument NPs. Stating constraints on quantifier scope in certain argument structures and explaining 'operator-free' nominal type coercion requires recourse to semantic frames, including quantifier frames.

- Effects of syntactic context. Certain verbs take certain complements only when negated, indicating that the complementation possibility in question is not a semantic property of the verb, but rather a constructional property.

This paper will be structured as follows. In section 2, I will provide a synopsis of SBCG. In section 3, I will discuss the five classes of phenomena described above. Section 4 will offer concluding remarks. 


\section{Sign-Based Construction Grammar}

SBCG uses the formal architecture of Head-Driven Phrase Structure Grammar (HPSG; Pollard and Sag 1987, Pollard and Sag 1994, Ginzburg and Sag 2000) to model the range of idiomatic patterns targeted by the Berkeley Construction Grammar framework (BCG; Fillmore et al. 1988, Goldberg 1995, Kay and Fillmore 1999, Kay 2002, and Michaelis and Lambrecht 1996). The goal of SBCG is to enhance the formal precision of BCG while also expanding the range of linguistic phenomena covered by HPSG. The fusion of the two frameworks is made possible by their shared foundational assumptions. Both assume that grammar, rather than representing a series of modules through which linguistic information is passed in the course of a derivation, is a network of linguistic patterns defined by constraints on form, meaning and use. Both BCG and HPSG are declarative, non-modular models of grammar. That is, both assume interpretations to be directly associated with rules of syntax, rather than being 'read off' syntactic representation once they are passed to an interpretive component of the grammar.

In SBCG, the basic object of grammatical description is the sign. A language is taken to be an infinite set of signs, and a grammar is taken to be a description of the recursive embedding of signs that constitutes the target language. While the term sign is understood in something close to its Saussurean sense, as a pairing of form and meaning, signs in SBCG are used to model not only words and lexemes but also phrases. Signs are types of linguistic objects and are organized by means of a type hierarchy (e.g., the sign type word is a subtype of the sign type lexical-sign, as is the sign type lexeme). Formally, a sign is a feature structure that specifies values for the features listed in (15-19): 
(15) SYN(TAX) describes the grammatical behavior of a sign. Its values are the features CAT(EGORY) and VAL(ENCE). The values of CAT are complex syntactic categories, represented as typed feature structures, e.g., noun, verb, preposition. The VAL feature represents the objects with which a given sign can combine. The VAL value of pronouns, proper nouns and most common nouns is an empty list. The VAL value of a verb is its combinatoric potential; for example, the VAL value of a transitive verb is $<\mathrm{NP}, \mathrm{NP}\rangle$.

(16) ARGUMENT STRUCTURE (ARG-ST) is a ranked list of the participant roles assigned by a predicator, along with any lexically assigned case properties of those participant roles. Unlike VAL, ARG-ST is a feature only of lexical entries (not of phrases).

(17) SEM(ANTICS) describes the meaning of a sign; its values are the features INDEX and FRAMES. INDEX is the extension of a sign. The FRAMES feature is used to enumerate the predications that together specify the meaning of a sign. Among the frames that will be relevant to us here are quantifier frames. For example, the meaning of the indefinite article $a$ in English is represented by means of an existential-quantifier frame.

(18) FORM is used to specify the morphological properties of a given sign; the value of FORM is a list of morphological entities. PHON(OLOGY) describes the phonological phrase corresponding to a given sign.

(19) CONTEXT (CTXT) is used to specify features of context that are relevant to the interpretation and use of a given sign. The values of CTXT include topic and focus.

Constructions in SBCG are descriptions of the possible signs and sign combinations in the target language. SBCG recognizes two kinds of constructions: lexical-class constructions, which describe properties common to sets of words and lexemes (e.g., the class of transitive verbs), and combinatoric constructions, which describe classes of constructs (Sag 2010, 2012, Michaelis 
2012). A construct can be viewed as a local tree licensed by a rule of the grammar. However, the SBCG description language does not include trees; SBCG contains no linguistic constraints that make reference to global properties of trees (e.g., c-command and subjacency). Instead, the combinatory constructions that describe possible constructs of the language are simply feature structures that contain a MOTHER (MTR) feature and a DAUGHTERS (DTRS) feature. An example of a combinatoric construction in English is the Subject-Predicate construction.

Like the phrase-structure rules of context-free grammar, combinatoric constructions build phrases like simple clauses and VPs, but they also do some work that phrase-structure rules do not: they build words (e.g., the third-person singular form of the lexeme laugh) and lexemes (e.g., the causative lexeme corresponding to the inchoative lexeme boil). Constructions of the former type are called inflectional constructions and constructions of the latter type are called derivational constructions.

Accordingly, the grammar is viewed as consisting of a lexicon-a finite set of lexical descriptions (descriptions of feature structures whose type is either lexeme or word) and a set of constructions. Figure 1 gives an example of a lexeme description: 
Figure 1. A Lexeme Description

$$
\left[\begin{array}{l}
\begin{array}{l}
\text { lexeme } \\
\text { FORM drink }
\end{array} \\
\text { SYNIVAL }\left\langle\mathrm{NP}\left[\begin{array}{l}
\text { overt } \\
\mathrm{INST} i
\end{array}\right], \mathrm{NP}\left[\begin{array}{l}
(\text { ini }) \\
\mathrm{INST} x
\end{array}\right]\right\rangle \\
\text { SEMIFRAMES }\left\langle\left[\begin{array}{l}
\text { drink-fr } \\
\text { DRINKER } i \\
\text { DRAFT } x
\end{array}\right],\left[\begin{array}{l}
\text { animate-fr } \\
\mathrm{INST} i
\end{array}\right],\left[\begin{array}{l}
\text { liquid }-f r \\
\mathrm{INST} x
\end{array}\right]\right\rangle
\end{array}\right]
$$

Figure 1 is a lexical entry describing the English lexeme drink. The semantic properties of this lexeme are represented by a series of frames (e.g., the frame abbreviated as drink-fr). Frames are used to capture the requirement that the drinker be animate and that the consumed item be a liquid. The combinatoric properties of this lexeme are represented in its valence set, which includes two noun phrases - the first of which is coindexed with the 'drinker' participant in the drink semantic frame and the second of which is coindexed with the 'draft' participant in the drink frame. In addition, each valence member (or valent) is tagged with a feature that represents its instantiation properties: the first valent (the subject NP) is obligatorily instantiated, while the second is optionally null instantiated. As indicated, the second valence member, when null instantiated, has an indefinite or, equivalently, existential interpretation. For example, sentence (20) means something like 'She drank some liquid substance from a plastic mug' (Fillmore 1986):

(20) She drank from a plastic mug. 
Figure 2 shows an inflectional construct licensed by the preterite construction, an inflectional construction that yields past-tense word forms of a verb lexeme (in this case, the lexeme laugh):

Figure 2. An Inflectional Construct

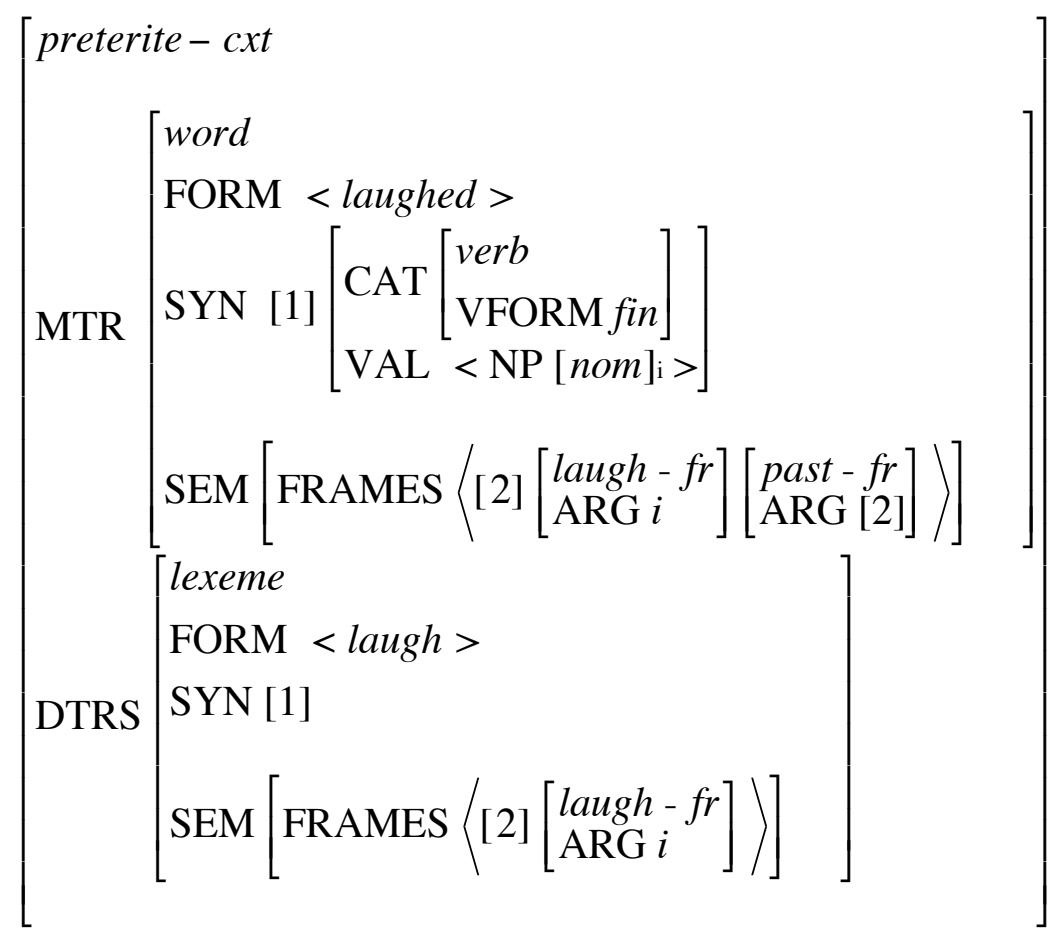

As an inflectional construct, this construct has a word as mother and a lexeme as daughter. The two occurrences of the tag [1] indicate that the SYN values of mother and daughter are identical. The past-tense meaning contributed by the construction is represented by the frame labeled past$f r$ in the mother's frame set. The single argument of this frame is the frame expressed by the verb lexeme (i.e., the laugh-frame), as indicated by the two occurrences of the tag [2] in the MTR.

Figure 3 shows a derivational construct of a type that will recur in our discussion of the quantification of argument NPs in section 3.4 below: 
Figure 3. A Derivational Construct

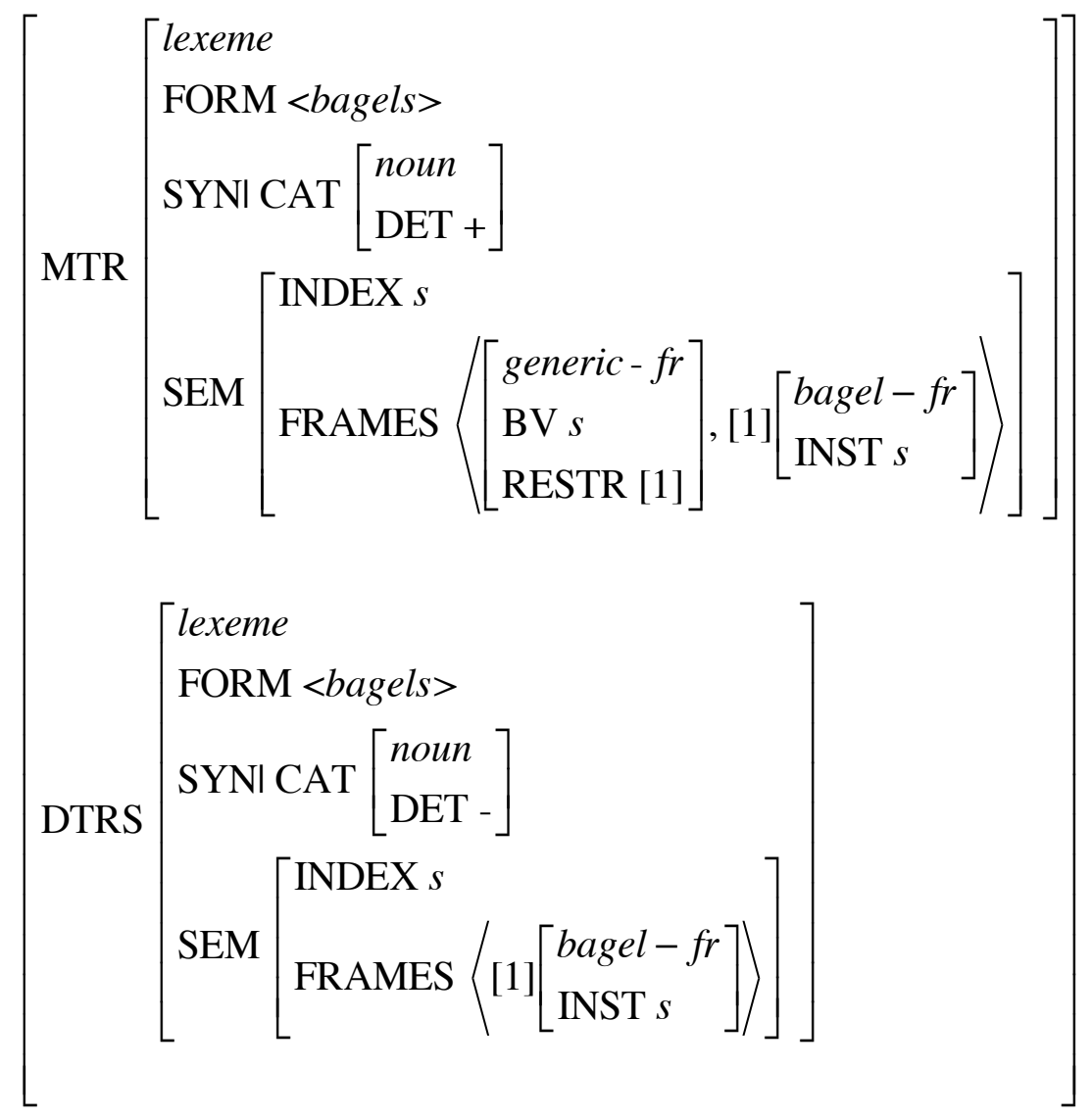

As in all derivational constructs, both the mother and daughter signs are lexemes. This particular construct is licensed by an English construction that we may refer to as the Bare Noun Pumping construction. Bare Noun Pumping yields determinerless plural NPs capable of occupying grammatical-function positions, as in (21-22):

(21) Bagels are boiled.

(22) We served bagels.

Bare nominal expressions can serve as arguments insofar as they receive quantified interpretations. In (21), for example, the bare plural noun bagels is interpreted as expressing 
universal quantification over individuals of the type bagel, while in (22) it is interpreted as expressing an existentially quantified aggregate (in terms of Chierchia 2003). This means the bare nominal construction must supply a quantifier that would otherwise be supplied by a determiner. In fact, it appears that there must be two derivational constructions for bare plurals in English: one that provides for generic quantification of undetermined noun phrases and another that provides for existential quantification of undetermined noun phrases. The nominal construct in Figure 3 is licensed by the former construction; generic quantification is represented by the generic frame in the construction's MTR. The variable bound by the quantifier is represented as an argument of the quantifier frame (BV), as is the restriction on the range of the quantifier (RESTR). The letter $s$ used to represent the bound variable is intended to capture its ontological type (aggregate or, equivalently, sum individual).

What we have seen of the SBCG formalism in this section is, I hope, sufficient to convey the scope of the model: constructions are used not only to represent the composition of phrases but also lexical classes (lexical-class constructions), the realization of morphological categories (inflectional constructions) and the addition of semantic features (derivational constructions). The SBCG approach to verbal argument structure departs from that of BCG, in which argumentstructure constructions were uniformly one-level. In BCG, argument-structure constructions were treated as schematic verb entries with which verbs unified in order to ensure grammatical expression of their semantic roles. In cases of valency mismatch like (45) above, the construction supplies whatever arguments the verb lacks. In SBCG, by contrast, only the two-level derivational constructions, and not lexical-class constructions, perform valence augmentation. The SBCG alternative, as described by Sag (2012: 115-16), involves a two-step analysis. First 
an intransitive verb lexeme (e.g., pant) is licensed with the singleton ARG-ST list characteristic of all strictly intransitive verbs. Second, another lexeme, whose ARG-ST list contains a directional expression (e.g., pant up to the sky-high altar) is built from this lexeme via a derivational construction whose MTR sign is a directed-motion lexeme. This constructed lexeme has a longer ARG-ST list than does its daughter lexeme. Derivational constructions capture the effect of lexical rules without requiring conservation of verbal thematic structure (Michaelis and Ruppenhofer 2001: Chapter 1).

Common to all construction-based approaches is the idea that a verb's array of arguments, and the manner of each argument's realization, is determined by the argument-structure construction with which the verb combines. In this fundamental respect, construction-based models differ from lexicalist approaches like that of RHL, in which a verb's argument-licensing properties are determined by its Aktionsart representation and the morphosyntactic expression of its arguments by realization rules. The evidence to be reviewed in the following section will suggest that verb frames are not built up via operations on semantic structure but rather licensed by templates that constrain the syntax, semantics and discourse status of the arguments in quite detailed ways.

\section{Evidence against an Aktionsart-driven Model of Argument Structure}

In this section, I will discuss five lines of evidence which converge to suggest that a verb's argument structure is determined by the construction with which it combines rather than by its Aktionsart structure, derived or otherwise. The evidence comes from aspectual underspecification (3.1), null complementation (3.2), the special-case nature of rules governing 
syntactic sisterhood relationships (3.3), quantification of argument NPs (3.4) and effects of syntactic context (in particular, negation) on verb's combinatoric potential (3.5).

\subsection{Aspectual Underspecification}

Recall that, according to RHL, a verb's valence is a reflex of its Aktionsart class, and valence variability occurs when a verb has multiple Aktionsart classes, related to one another by semantic transformations. There are, however, numerous argument-structure patterns that appear neutral with regard to Aktionsart. The English transitive pattern appears to be one such example. As an illustration, consider instances in which the verb walk appears as a transitive, with a direct object denoting the surface covered. Such predications may be telic, as in (23), or atelic, as in (24):

(23) Accomplishment: This would be bad except the dearth of things to see meant we'd walked the floor in 70 minutes.

(24) Activity: He walked the floor for half an hour puzzling over his enigma.

The evidence for telicity in each case comes from the temporal adverbials used: the in-headed frame adverbial combines only with telic predications, as in (23), while the for-headed durational adverbial combines only with atelic predications, as in (24). The problem is that both examples would count as instances of template augmentation, in particular augmentation of an activity representation up to that of an accomplishment: [[x ACT $<M A N N E R>$ ] CAUSE [BECOME $\mathrm{y}$ $<$ STATE $>]]$. There is no other obvious means by which the otherwise intransitive walk would receive a direct object denoting a surface. The verb walk, as a self-motion verb, selects for an oblique second argument denoting a path or direction, but, as a self-motion verb, it does not intrinsically denote coverage of a surface, as it does in (23-24). While it seems reasonable to 
conclude that (23) is an instance of template augmentation (activity $\rightarrow$ accomplishment), example (24) remains unaccounted for. If it is an accomplishment, it should be telic, but the presence of the durational adverbial headed by for in (24) demonstrates that this predication is in fact atelic. We must conclude that the transitive pattern illustrated in (23-24) is underspecified with regard to telicity. While one might be tempted to associate the locative-object (or, equivalently, applicative) pattern with accomplishment Aktionsart, insofar as the pattern implies 'affectedness', 'coverage' or 'saturation' of the location denoted by the object NP, it appears that applicative verbs have both telic (accomplishment) and atelic (activity) construals. Whatever the meaning of the applicative pattern, it cannot be exclusively Aktionsart-based. In a constructionbased model of valence augmentation, however, the meanings of argument-structure patterns are unconnected to Aktionsart representations. Aspectual underspecification is therefore expected.

\subsection{Null Complementation}

The RHL model makes three predictions about null complementation (Ruppenhofer and Michaelis 2014; Goldberg 2000, 2005). These are given in (25-27):

(25) As nonstructural arguments, the second arguments of bivalent state, achievement and activity verbs should always be omissible.

(26) Nonstructural participants are subject only to a recoverability condition based on prototypicality (RHL: 115); therefore all null complements should have existential (indefinite) interpretations.

(27) As structural arguments, patient arguments of accomplishment verbs should never be omissible. 
Each of these predictions proves false. First, as shown in (28-30), it is not the case that all bivalent state, achievement and activity verbs allow omission of their second arguments:

(28) State: She resembles *(Aunt Molly).

(29) Achievement: I found *(my watch).

(30) Activity: We discussed *(the issue).

Second, as shown in (31-34), null instantiated second arguments of verbs in these Aktionsart classes do not necessarily have an existential interpretation; such arguments often have anaphoric interpretations:

(31) State: My feelings are similar (to yours).

(32) State: I remember (that).

(33) Achievement: I won (the race).

(34) Activity: I prepared (for that event) for weeks.

Third, as observed by Goldberg (2005), patient arguments of accomplishment verbs are in fact omissible, despite the fact that that these are ipso facto structural arguments in the RHL model: verbs of emission/ingestion like spit, swallow allow omission of their patient arguments (as in, for example, He spat onto the sidewalk) and, as shown in (35-37), almost any verb, including an accomplishment verb, allows existential null complementation of its second argument in an iterated-event context:

(35) Owls only kill (things) at night. 
(36) China produces (things) and the US imports (things).

(37) She has never failed to impress (people).

Additional problematic aspects of the RHL model of null complementation are as follows. First, null-instantiated complements of nonverbal predicators, illustrated by (3840), simply remain unexplained, because such predicators presumably lack Aktionsart structure:

(38) Noun: Make me a copy (of that).

(39) Preposition: She walked over (here).

(40) Adjective: I'm taller (than you).

Second, as observed by Ruppenhofer (2012), null-complementation affordances of verbs are affected by context; when a motion verb is interpreted as denoting a path shape rather than actual movement, it does not generally allow omission of its landmark argument:

(41) Actual motion: Where did she cross (the road)?

(42) Fictive motion: Where does Highway 42 cross *(Highway 287)?

Although fictive- and actual-motion verbs do differ aspectually (the former being stative and the latter dynamic), the null-complementation split in (41-42) is the reverse of the one predicted by 
the RHL model, which treats the second arguments of state verbs, but not accomplishment verbs, as omissible.

The flip side of valence reduction is valence augmentation, and this phenomenon too presents problems for an Aktionsart-driven model of argument structure. Recall from Table 1 that, in the RHL model, accomplishment verbs like break have the Aktionsart representation $x$ CAUSE [BECOME y $<S T A T E>$ ]. Recall too principle (8): Each XP must correspond to a subevent. Given these two conditions, we have no easy way to account for the well formedness of (43-44):

(43) She crumbled the crackers into the soup.

(44) The snow broke the branches off the tree.

The above examples should be ungrammatical, because in each a directional expression (into the soup or off the tree) denotes a resultant state distinct from that entailed by the verb's Aktionsart representation (the resultant states of being crumbled and broken, respectively). These PPs therefore are XPs that do not correspond to a subevent, in violation of (8). The facts in (43-44) are, however, captured by a construction-based model: the verb denotes the means by which a causation-of-motion event, denoted by the construction, occurs. For example, in (43), crumbling is construed as the means by which the crackers are moved from one location (the agent) to another (the soup).

The constructional account of argument-structure treats verb-valence variability as the product of constructional affordances, and not as effects of a verb's semantic representation, whether basic or altered via semantic transformation. The constructional account does not, for example, assume a class of 'structurally intransitive' verbs. Instead, it posits an array of derivational constructions that build verb lexemes of a particular type: those which allow a particular argument to be unexpressed (for details, see Michaelis 2012: 53-54). These 
constructions, which include the existential perfect construction, license verb lexemes that have the instantiation properties of the lexeme drink in Figure 1. Recall that the 'draft' argument of drink is subject to (indefinite) null instantiation. Through these derivational constructions, the grammar licenses, for example, a verb lexeme kill that has a (potentially) null-instantiated 'victim argument'. This kill lexeme is then a potential daughter lexeme for a null-instantiation construction. Null-instantiation constructions are derivational constructions that effectively remove arguments from a verb's valence list, while ensuring that the quantifier frame of the nullinstantiated argument remains in the MTR verb's ARG-ST list. According to Michaelis (2012), the MTR lexeme's semantic frames include the quantifier frame missing from the valence set of the daughter, as well as a frame that indicates whether the null-instantiated argument is construed anaphorically, as in (31-34), or existentially, as in (35-37). An example of a null-instantiation construction is that which licenses existentially interpreted null-instantiated theme arguments of emission verbs, for example, spit, sneeze (Goldberg 2005). Evidence for this construction comes from coercion phenomena involving verbs of vision:

(45) She frowned into the mirror.

(46) She glanced over her shoulder.

Neither frown nor glance semantically selects for a directional argument; it is only via combination with the construction that licenses an existentially construed null-instantiated theme argument that these verbs may be augmented up to causation-of-motion verbs. Such augmentation involves a metaphorical construal of vision in which an 'eye beam' moves from one location, the perceiver, to another, the percept (Slobin 2008). What might seem paradoxical — that a 'subtraction' construction here adds an argument (a directional expression) to a verb of vision - makes sense on the constructional account: the construction that licenses 
verbs of emission that have an unexpressed theme argument denotes an event of transfer. That is, the SEM value of the MTR contains a trivalent transfer frame. In addition to capturing such coercion effects, null-complementation constructions enable us to account for override effects involving null complementation restrictions on verbs. While, as observed above, accomplishment verbs do not select for null-instantiated theme arguments when construed episodically, they do when construed iteratively, as shown in (35-37). We can therefore conclude, following Goldberg (2005), that aspectual constructions like the existential perfect construction carry constraints on argument instantiation, allowing indefinite null complementation in examples like (37). Such cases demonstrate that constructions can alter the combinatoric properties of the verbs with which they combine.

\subsection{Weird Sisterhood}

A number of argument-structure patterns involve verbal complementation patterns that are not licensed by the general-purpose head-complement or specifier-head phrase-building rule schemas. Many of these patterns have specialized communicative functions. A look at these phenomena suggests that highly detailed constructions, rather than non-category-specific phrasestructure rules, pair predicates and their complements. In this section, we will look at three cases of weird sisterhood found in English: Nominal Extraposition, Just Because and Hypotactic Apposition. The data discussed in this section are taken from two corpora of English telephone conversations available through the Linguistic Data Consortium (www.ldc.upenn.edu): the Switchboard corpus (sw) or the Fisher corpus (fe).

\subsubsection{Nominal Extraposition.}


In Nominal Extraposition, an exclamatory adjective, for example, amazing, licenses an NP complement:

(47) I know it's just it's unbelievable the different things that are happening in America today. (sw03982B)

(48) I'll date myself a little bit but it it's remarkable the number of those things they need. (sw02392B)

(49) I know. I love that game. It's amazing the words they come up with. (fe_03_08039A)

The pattern exemplified in (47-49) is idiosyncratic in two respects. First, adjectives are not case assigners and should not therefore license non-oblique NP complements. Second, this NP complement is interpreted as denoting a scalar degree (Michaelis and Lambrecht 1996). In (49), for example, the NP the words they come up with stands in for a scalar expression like 'the number of words they come up with' or 'the quality of the words they come up with'. The fact that the complement of amazing in (49) has a scalar interpretation follows from the fact that (49) is an exclamation, but the pairing of an exclamatory adjective with an NP sister that denotes a degree, metonymically or otherwise, requires a construction that provides for this syntax and this meaning.

\subsubsection{Just Because}

In the Just Because construction, a negated epistemic verb, typically mean, licenses a finite clause subject introduced by the subordinating conjunction just because (Bender and Kathol 2001): 
(50) Just because they use primitive means of doing things does not mean that they can't expand.(fe_03_06870A)

(51) Just because they say it doesn't mean that's the only way to look at it. (fe_03_00135A)

Clausal subjects are ordinarily introduced by that, not a subordinating conjunction like because, so we cannot use the general-purpose constituency rule that pairs a specifier with a head to account for the pattern in (50-51). Instead, as Bender and Kathol argue, the grammar of English must contain an argument-structure construction that allows the verb mean, when negated, to license a clausal subject introduced by just because.

\subsubsection{Hypotactic Apposition}

When English speakers use a cataphoric demonstrative pronoun to announce forthcoming propositional content, they may do so by means of either the paratactic construction in (52) or the subordinating construction in (53-54), the latter of which Brenier and Michaelis (2005) refer to as Hypotactic Apposition:

(52) That's what I've been telling you: you need to call.

(53) That's the problem is that they just hate us so much and I never re- I never really realized. (fe_03_01019A)

(54) That's the main thing is that I can't tell whether the thing is going to fit. (sw03729A)

In Hypotactic Apposition, the copula licenses two arguments that it would not license ordinarily: a clause containing a cataphoric pronoun and a clausal complement that is coreferential with the cataphoric pronoun contained in its clausal sister. This is not the licensing behavior of equational 
be, as found, for example, in The problem is that they just hate us so much; it is the licensing behavior of the Hypotactic Apposition construction.

\subsection{Argument Quantification}

In quantifier-scope hierarchies, the quantifiers of topical and/or subject referents outscope those of nontopical and nonsubject referents (Ioup 1975, Kuno 1991). While these hierarchies capture robust cross-linguistic interpretive tendencies, they do not explain scope constraints in certain argument-structure patterns. The two argument-realization patterns that we will consider here are discussed in detail by Basilico (1998). They are the creation pattern, exemplified by (55), and the transformation pattern, exemplified by (56):

(55) Creation: She made a paperweight from a rock.

(56) Transformation: She made a rock into a paperweight.

The creation-transformation alternation hinges on whether the 'raw material' role (in this case, the rock) is played by a source argument, from a rock, as in (55), or a theme argument, a rock, as in (56). In the latter (transformation) case, the 'product' role is played by an oblique goal argument. In the creation pattern, both the theme argument and the source argument can take narrow scope, as shown in (57-58), respectively:

(57) Narrow scope theme argument: A mighty oak grew from every acorn.

(58) Narrow scope source argument: Every oak grew from a tiny acorn.

In the transformation pattern, however, the theme argument must take wide scope, as in (59):

(59) Every acorn grew into a beautiful oak. 
Evidence for this quantifier-scope constraint comes from semantic anomalies like (60), where the \# symbol indicates that the sentence is well formed but has a bizarre interpretation:

(60) Wide scope theme argument: \#An acorn grew into every oak.

In (60), the theme argument necessarily has wide scope: this sentence can only be interpreted as asserting 'There exists a single acorn from which all of the oaks grew'. This scoping creates a nonsensical reading: we know that one acorn cannot produce many oaks. There are two plausible ways to explain why (60) has the anomalous reading it does. The first explanation is based on the quantifier-scope hierarchy: the sensible interpretation of (60), in which there is a one-to-one mapping between oaks and acorns, requires the quantifier of an oblique argument (the universal quantifier of into every oak) to have wide scope relative to the quantifier of the subject argument (the existential quantifier of an acorn). Since this scoping violates the quantifier-scope hierarchy, (60) has only the nonsensical reading. The second explanation involves topicality: subject NPs are grammaticalized clause-level topics (Mithun 1991, Lambrecht 1994: Chapter 4), and as such tend to have specific referents. Because the sensible reading of (60) requires that the subject NP an acorn receive a nonspecific reading, in which it denotes any acorn rather than a unique acorn, (60) is anomalous. As shown by (61), however, both explanations fail to generalize:

(61) An oak grew out of every acorn.

In (61), an instance of the transformation pattern, the subject is a theme argument, just as it is in (60). Further, this subject NP is both nonspecific and scoped by an oblique argument (every acorn). And yet (61) has a sensible interpretation, in which there is a one-to-one mapping between oaks and acorns, while (60) does not. This suggests that what gives (60) the nonsensical reading it has is a constraint specific to the transformation pattern. I propose that the 
transformation pattern constrains its locative argument in a way that the creation pattern does not. The creation pattern allows its locative argument (i.e., the source argument) to be either topic or focus. This is shown in (62-63), respectively, where the points of prosodic prominence are indicated by small caps:

(62) Topical source argument: An OAK grew out of it.

(63) Focal source argument: That oak grew out of an ACORN.

The transformation pattern, by contrast, is pragmatically constrained. Its locative argument (i.e., its goal argument) is necessarily interpreted as focal. This is shown by the ungrammaticality of (64), in which the goal argument is topical (as indicated by its pronominal expression), as compared to (65), in which the goal argument is focal (as indicated by its prosodic prominence):

(64) Topical goal argument: *A tiny acorn grew into it.

(65) Topical theme argument: The tiny acorn grew into an OAK.

Unlike the goal argument, the theme argument of the transformation pattern must be assigned a topic role, as indicated by the ungrammaticality of both the intransitive (66) and the transitive (67):

(66) *A tiny ACORN grew into that old oak.

(67) *I made a ROCK into a paperweight.

As a topic, the theme argument of the transformation pattern cannot readily be interpreted as nonspecific; this follows from Lambrecht's Topic Acceptability Hierarchy (Lambrecht 1994: 165-171). Because it must be interpreted as denoting a specific entity, an existentially quantified theme argument in the transformation pattern cannot take narrow scope relative to a universally 
quantified goal argument,. This leads to the nonsensical reading in (60), in which an acorn denotes a single acorn. To represent such constraints we must characterize the arguments licensed by verbs in terms of their pragmatic roles, for example, topic and focus. As shown in Table 1, event-structure templates of the type proposed by RHL contain unbound variables in place of arguments. While the semantic role of an argument can be inferred from its position in decompositional structure, its pragmatic role cannot. SBCG constructions provide a simple way to describe contextual features of argument roles of verbs. The lexical-class constructions of SBCG have ARG-ST sets whose members are sign descriptions. The signs described are coindexed with arguments of frames within the construction's SEM value. These frame arguments can in turn be coindexed with arguments of the construction's CTXT attribute. The (intransitive) transformation pattern, which licenses verbal lexemes like grow as in (59), is represented by the lexical class construction shown in Figure 4:

Figure 4. The Intransitive Transformation Lexical Class Construction

$$
\left[\begin{array}{l}
\text { transform }-i v-l x m \\
\operatorname{ARG}-\mathrm{ST}\left\langle\mathrm{NP}_{x}, \mathrm{PP}_{y}\right\rangle \\
\text { SEMIFRAMES }\left\langle\left[\begin{array}{l}
\text { transform }-f r \\
\text { MATERIAL } x \\
\text { PRODUCT } y
\end{array}\right]\right) \\
\mathrm{CTXT}\left[\begin{array}{l}
\text { discourse }- \text { role } \\
\text { TOPIC } x \\
\text { FOCUS } y
\end{array}\right]
\end{array}\right]
$$

Another interpretive phenomenon that suggests that verb classes constrain the quantification of their arguments is one that I will call operator-free nominal coercion. Nominal coercion is reinterpretation of a nominal in order to resolve conflict between the type required by an operator and the type of the nominal argument supplied (Jackendoff 1997: Ch. 3). For example, the 
English partitive article some induces the interpreter to construe the noun pillow as denoting a mass rather than a bounded entity in *some pillow. However, an operator-based model of nominal coercion only goes so far; it does not explain the interpretive effects evident in (68-69):

(68) Apple dries easily.

(69) You have apple on your shirt.

Neither $d r y$ nor have selects a mass-type second argument, so what can account for the portion or type reading of apple in these contexts? As discussed in section 3.2 above, arguments of verbs, whether phonetically instantiated or not, have to be quantified. This requirement is represented in SBCG by associating a quantifier frame with each of the verb's ARG-ST elements in the lexicalclass construction that represents that verb's lexical class. Lexical classes are broad, and include transitive verb lexemes, intransitive verb lexemes, and so on (Sag 2012: 100ff). In English, the primary means by which a common noun gets a quantified interpretation is through combination with a determiner. The only other way is through the Bare Noun Pumping Construction shown in Figure 3. As discussed there, this construction yields existentially and generically quantified interpretations of undetermined nouns. What triggers the use of this pumping construction? Simply put, it is the requirement that the nominal arguments of a predicator be quantified. Aktionsart representations do not contain quantifiers, but lexical-class constructions do. As we saw earlier in this section, lexical-class constructions contain FRAMES among their semantic attributes. These frames include quantifier frames.

\subsection{Effects of Syntactic Context}

In a lexically driven model of verbal argument selection, it is assumed that a verb will select the same repertoire of complements irrespective of the syntactic context in which it appears. This is 
because syntactic context does not affect lexical-class membership, whether the lexical class in question is syntactic (the class of extraposition verbs that includes seem and appear) or semantic (the class of transfer verbs). Against this background, the following facts seem genuinely puzzling:

(70) [If I don't answer] it's *(not) that I don't want to..

(71) I *(can't) believe how much weight I've gained!

The main clause in (70) illustrates a construction referred to by Delahunty (2001) as the inferential sentence type or sentence-focus cleft. Inferential sentences assert that some state of affairs (the one following the copula) is responsible for a state of affairs under discussion. An attested example of an inferential sentence is shown in (70), where the inferential sentence is boldfaced:

(72) And it never fails if they have a cat [laughter]. It's gonna sit on my lap and I get hives and my throat swells up when I get near a cat. And it's not that I don't like 'em. I'm just allergic to them and it never fails when I go in the home. (fe_03_06266A)

What makes the attested inferential sentence in (72) well formed while the starred version in (70) is not? The simple answer is: the presence of negation in the attested example. English inferential clefts either serve to reject, or presuppose rejection of, a potential explanation for the state of affairs under discussion. In the case of (72) the speaker rejects 'dislike of cats' as the cause of her avoidance of cats. A speaker who uses an inferential sentence might follow up by asserting an actual cause, and this cause is typically presented as less extreme, on some pragmatic scale, than the previously rejected one. In (72), the purported actual cause is the speaker's allergies: I'm just allergic to them. Assertion of the actual cause might itself take the form of an inferential 
cleft, resulting in the sequence It's not that $S$; it's just that $S$. Thus, both the negative morpheme and the adverbial minimizer just are closely associated with inferential sentences. However, it would make little sense to say that the copula be selects the complements it and that $S$ just in case it is accompanied by not or just. The adverbial-modification facts make sense only under a construction-based account that attributes very specific use conditions to the inferential cleft sentence type.

Something similar can be said in the case of (71). In (71), we see that the verb believe takes a WH-interrogative complement only in case it is negated. Again, this fact would be inexplicable in a lexical model of complement selection, in which verbs take the complements they do by virtue of their lexical classes. There is no lexical class of 'negated verbs'. Instead, the negation requirement in (71) appears to be a constructional effect. Michaelis and Lambrecht (1996) call the construction in question the Abstract Exclamative Construction (AEC), and claim that all exclamatory sentences encode the discourse-pragmatic 'ingredients' of the AEC in some form. Exclamatory sentences, according to their analysis, express that the degree of some scalar property (e.g., weight), as achieved by some topical referent (e.g., the speaker), is sufficiently extreme to cause expectation violation. Expectation violation may be expressed by an adjective like amazing or remarkable, an interjection like God or a negated verb of belief. The scalar degree is typically encoded by the WH-phrase of a WH-interrogative (e.g., how much weight I've gained). Thus, the verb believe has the complement it does in (71) because, in the context of an exclamatory utterance, it is functioning to encode expectation violation. The moral of the story is yet again that constructions - whether concrete, like the inferential sentence type, or abstract, like the AEC — determine the combinatoric potentials of verbs. 


\section{Conclusion}

The evidence that we have reviewed here suggests that verbal argument structure is not derived from or 'read off' semantic representation. On the alternate approach described here, verbs license the arguments that they do because they combine with constructions that (a) determine what semantic and syntactic elements will accompany the verb, (b) provide quantifiers for each argument, (c) determine which argument will be topic and which focus and (d) add to the array of semantic and pragmatic frames that the verb has independently. These constructions include both derivational constructions like the Null Instantiation construction and lexical-class constructions like the Intransitive Transformation construction. On this approach, semantic roles exist only in theta frames (e.g., causation of result and caused motion); there is no semantic-role hierarchy of the type used to assign grammatical functions in most current accounts of argument structure, including RHL. As Fillmore and Kay (1995) point out, the semantic-role hierarchy, despite its widespread currency, is a poor candidate for a linguistic generalization because it features combinations of semantic roles that no verb would ever license. Theta frames, by contrast, express only those semantic-role sets that play a role in verb-valence descriptions. But no speaker ever encounters a naked theta frame: the generalizations about semantic-role combinations that speakers learn and use are theta frames as expressed by morphosyntactic patterns, and these morphosyntactic patterns, as we have seen, contain a good deal of idiomatic information about meaning, use and form. In sum, the study of verbal complement licensing, like Bybee's studies of the inflectional morphology (Bybee 2001), could be said to demonstrate that linguistic generalizations are simply not that general. 


\section{References}

Basilico, D. (1998) 'Object Position and Predication Forms'. Natural Language and Linguistic Theory 16 (3): 491-539.

Bates, E. and J.C. Goodman (1997) 'On the Inseparability of Grammar and the Lexicon: Evidence from Acquisition, Aphasia and Real-time Processing' Language and Cognitive Processes 12 (5/6): 507-584.

Bender, E. and A. Kathol (2001) 'Constructional Effects of Just Because...doesn't Mean...', paper presented at the Twenty-Seventh Annual Meeting of the Berkeley Linguistics Society. Berkeley, CA.

Birner, B. J. and G. Ward. (1998) Information Status and Noncanonical Word Order in English (Amsterdam/Philadelphia: John Benjamins).

Boas, H. and I. A. Sag (eds.) Sign-Based Construction Grammar (Stanford: CSLI Publications).

Brenier, J. M. and L. A. Michaelis (2005) 'Optimization via Syntactic Amalgam: SyntaxProsody Mismatch and Copula Doubling' Corpus Linguistics and Linguistic Theory 1(1): $45-88$.

Bresnan, J. (1994) 'Locative Inversion and the Architecture of Universal Grammar' Language 70 (1): $72-131$.

Bresnan, J. (2001) Lexical-Functional Syntax. (Oxford: Blackwell).

Bybee, J. (2001) Phonology and Language Use (Cambridge: Cambridge University Press).

Chierchia, G. (2003) 'Language, Thought and Reality after Chomsky' unpublished ms., University of Milan-Bicocca. 
Croft, W. (1991) Syntactic Categories and Grammatical Relations (Chicago: University of Chicago Press).

Croft, W. (2012) Verbs: Aspect and Causal Structure (Oxford: Oxford University Press).

Delahunty, G. 2001. 'Discourse Functions of Inferential Sentences' Linguistics 39 (3): 517-545.

Dowty, D. (1979). Word Meaning and Montague Grammar: The Semantics of Verbs and Times in Generative Semantics and in Montague's PTQ (Dordrecht: Kluwer Academic Publishers).

Fillmore, C. J. (1986) 'Pragmatically Controlled Zero Anaphora' in V. Nikiforidou, M. Van Clay, M. Niepokuj, and D. Feder (eds) The Twelfth Annual Meeting of the Berkeley Linguistics Society (Berkeley: BLS, Inc), pp. 95-107.

Fillmore, C. J. and P. Kay (1995) Construction Grammar, Unpublished ms, University of California, Berkeley.

Fillmore, C. J., P. Kay and M. C. O'Connor (1988) 'Regularity and Idiomaticity in Grammatical Constructions: The Case of Let Alone' Language 64 (3): 501-538.

Ginzburg, J. and I. A. Sag (2000) Interrogative Investigations: The Form, Meaning and Use of English Interrogatives. (Stanford, California: CSLI Publications).

Goldberg, A. (1995) Constructions: A Construction Grammar Approach to Argument Structure. (Chicago: University of Chicago Press).

Goldberg, A. (2001) 'Patient Arguments of Causative verbs can be Omitted: The Role of Information Structure in Argument Distribution' Language Sciences 23 (4/5): 503-524.

Goldberg, A. 2002. 'Surface Generalizations: An Alternative to Alternations' Cognitive Linguistics 13 (4): 327-356. 
Goldberg, A. (2005) 'Constructions, Lexical Semantics and the Correspondence Principle: Accounting for Generalizations and Subregularities in the Realization of Arguments' in N. Erteschik-Shir and T. Rapoport (eds) The Syntax of Aspect. (Oxford: Oxford University Press), pp. 212-236.

Goldberg, A. (2006) Constructions at Work: The Nature of Generalization in Language (Oxford: Oxford University Press).

Haegeman, L. (1994) Introduction to Government and Binding Theory, second edition. (Oxford: Blackwell).

Ioup, G. (1975) ‘Some Universals for Quantifier Scope’ in J. Kimball (ed) Syntax and Semantics, volume 4. (New York: Academic Press), pp. 37-58.

Jackendoff, R. (1990) Semantic Structures (Cambridge, MA: MIT Press).

Jackendoff, R. (1997) The Architecture of the Language Faculty (Cambridge, MA: MIT Press).

Kaschak, M. and A. Glenberg (2000) 'Constructing Meaning: The Role of Affordances and Grammatical Constructions in Language Comprehension' Journal of Memory and Language 43 (3): 508-529.

Kaschak, M. and A. Glenberg (2002) 'Grounding Language in Action' Psychonomic Bulletin and Review 9 (3): 558-565

Kay, P. (2002) ‘English Subjectless Tag Sentences’ Language 78 (3): 453-81.

Kay, P. and C. J. Fillmore (1999) 'Grammatical Constructions and Linguistic Generalizations: The 'what's X doing Y' Construction' Language 75 (1): 1-33.

Kay, P. and L. A. Michaelis. (2012) Constructional Meaning and Compositionality in C. Maienborn, K. von Heusinger and P. Portner (eds) Semantics: An International Handbook of Natural Language Meaning. Vol. 3. (Berlin: de Gruyter), pp. 2271-2296. 
Kuno, S. (1991) 'Remarks on Quantifier Scope' in H. Nakajima (ed). Current English Linguistics in Japan. (Berlin: Mouton de Gruyter), pp. 261-287

Lambrecht, K. (1994) Information Structure and Sentence Form. (Cambridge: Cambridge University Press).

Levin, B. and M. Rappaport Hovav (2005) Argument Realization. (Cambridge: Cambridge University Press).

Levin, B. (2000) 'Aspect, Lexical Semantic Representation and Argument Expression' in L. J. Conathan, J. Good, D. Kavitskaya, A. B. Wulff and A. Yu (eds) The Proceedings of the Twenty-Sixth Annual Meeting of the Berkeley Linguistics Society (Berkeley: BLS, Inc.), pp. 413-429.

Michaelis, L. A. (2004) 'Type Shifting in Construction Grammar: An Integrated Approach to Aspectual Coercion’ Cognitive Linguistics 15 (1): 1-67.

Michaelis, L. A. (2009) 'Sign-Based Construction Grammar' in B. Heine and H. Narrog (eds) The Oxford Handbook of Linguistic Analysis (Oxford: Oxford University Press), pp. 155176.

Michaelis, L. A. 2012. 'Making the Case for Construction Grammar' in H. Boas and I. A. Sag (eds) Sign-Based Construction Grammar (Stanford: CSLI Publications), pp. 29-60.

Michaelis, L. A. and J. Ruppenhofer. (2001) Beyond Alternations: A Construction-Based Approach to the Applicative Pattern in German. (Stanford: CSLI Publications).

Michaelis, L. A. and K. Lambrecht (1996) 'Toward a Construction-Based Model of Language Function: The Case of Nominal Extraposition' Language 72 (2): 215-247. 
Mithun, M. (1991) 'The Role of Motivation in the Emergence of Grammatical Categories: The Grammaticization of Subjects' in E. C. Traugott and B. Heine (eds) Approaches to Grammaticalization, Volume 2 (Amsterdam: John Benjamins), pp. 159—184.

Moens, M. and M. Steedman (1988) 'Temporal Ontology and Temporal Reference' Computational Linguistics 14 (2): 15-28

Neidle, C. (1994) 'Lexical Functional Grammar' Encyclopedia of Language and Linguistics, volume 5 (New York: Pergamon Press), pp. 2147-2153.

Partee, B. and V. Borschev (2007) 'Existential Sentences, BE and the Genitive of Negation' in Russian' in K. von Heisenger and I. Comorovski (eds) Existence: Semantics and Syntax. (Berlin: Springer Verlag), pp. 147-190.

Pinker, S. (1989) Learnability and Cognition. (Cambridge, MA: MIT Press).

Pollard, C. and I. A. Sag (1987) Information-based Syntax and Semantics. Volume 1: Fundamentals (Stanford: CSLI Publications).

Pollard, C. and I. A. Sag (1994) Head-Driven Phrase Structure Grammar (Chicago: University of Chicago Press).

Rappaport Hovav, M. and B. Levin (1998) 'Building Verb Meanings' in M. Butt and W. Geuder, (eds) The Projection of Arguments (Stanford: CSLI Publications), pp. 97-134.

Ruppenhofer, J. (2012) 'Fictive Motion: Construction or Construal?' in Z. Antic, M. Babel, C. Chang, J. Hong, M. Houser, F.-C. Liu, M. Toosarvandani and Y. Yao (eds) The Proceedings of the Thirty-second Annual Meeting of the Berkeley Linguistics Society: Parasession on Theoretical Approaches to Argument Structure. (Berkeley: BLS, Inc.), pp. 307-319. 
Ruppenhofer, J., C. F. Baker and C. J. Fillmore (2002) 'Collocational Information in the FrameNet Database' in A. Braasch and C. Povlsen (eds) Proceedings of the Tenth Euralex International Congress, Volume I (Copenhagen, Denmark), pp. 359-369.

Ruppenhofer, J. and L. A. Michaelis (2014) 'Frames and the Interpretation of Omitted Arguments in English' in S. Katz Bourns and L. Myers (eds) Linguistic Perspectives on Structure and Context: Studies in Honor of Knud Lambrecht (Amsterdam: Benjamins), pp. $57-86$.

Slobin, D. I. 2008. 'Relations between Paths of Motion and Paths of Vision: A Crosslinguistic and Developmental Exploration' In V. M. Gathercole, (ed) Routes to Language: Studies in Honor of Melissa Bowerman. (Mahwah, NJ: Lawrence Erlbaum Associates), pp. 197-221.

Sag, I. A. (2012) 'Sign-Based Construction Grammar: An Informal Synopsis' in H. C. Boas and I. A. Sag (eds) Sign-Based Construction Grammar (Stanford: CSLI Publications), pp. 69202.

Sag, I. A. (2010) 'English Filler-Gap Constructions’ Language 86 (3): 486-545.

Van Valin, R. D. and R. J. LaPolla (1997) Syntax (Cambridge: Cambridge University Press). 


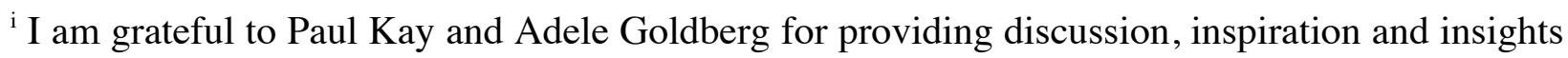
that have enriched and clarified the material presented here, although neither necessarily endorses my claims or analyses. This paper is dedicated to the memory of my friend and mentor Charles J. Fillmore. 